\title{
Phenoloxidase specific activity in the red swamp crayfish Procambarus clarkii
}

\author{
Washington Cárdenas and J ohn R. Dankert* \\ Department of Biology, I mmuno-E cology Laboratory, U niversity of \\ Southwestern Louisiana, Lafayette, LA 70504, U.S.A.
}

(R eceived 7 A ugust 1996, accepted in revised form 20 J anuary 1997)

\begin{abstract}
The prophenoloxidase (proPO) system is considered an important mechanism of innate defence in arthropods. This enzymatic cascade has been studied in crustaceans such as the crayfishes A stacus astacus and Pacifastacus I eniusculus and is located inside the haemocytes. An initial characterisation of this system in the commercially important red swamp crayfish P rocambarus clarkii is described. The P. clarkii proPO system was activated by trypsin and also by zymosan $A$. This activation was calcium ion dependent. The calcium ion concentration also affected the background activation of the system and at $5 \mathrm{~mm}$ was highest as measured by the ability of phenoloxidase to oxidise L-3,4-dihydroxyphenylalanine. The effect of calcium ions appears to be related to the activation of an endogenous serine protease, but other calcium ion-dependent factors can also affect proPO activation. Lipopolysaccharides (LPS), glycolipids found in the outer leaflet of the outer membrane of Gram-negative bacteria, were also able to activate the proPo system in P. clarkii after a significant lag time of 25 to $30 \mathrm{~min}$. However, LPS derivatives (deacylated LPS, lipid A and $\beta$-D-GICNAC-[1 $\rightarrow 6]-D-G I C N A C$ ) were not able to activate the enzymatic cascade in $P$. clarkii. A ctivation of the proP $O$ system in other crayfishes by LPS has been shown to be mediated by serine protease-like enzymes. The observed effect of LPS and LPS derivatives on the activation of the $P$. clarkii proPO system suggests that a protease activity triggered by these molecules may be mediated through the recognition of a "complete" LPS molecule (polysaccharide and lipid A). The intermolecular recognition of LPS by a putative endogenous serine protease zymogen might explain the lag time observed in propo activation.

(C) 1997 A cademic Press Limited
\end{abstract}

Key words: prophenoloxidase, haemocyte lysate, lipopolysaccharide, Procambarus clarkii, serine protease, zymosan.

\section{Introduction}

The prophenoloxidase activating system (proPO) is an enzymatic cascade associated with the pathogen defence mechanisms of arthropods (Söderhäll \& Smith, 1986; Rowley et al., 1986). In crustaceans proPO resides in the granular and semi-granular circulating haemocytes (Söderhäll \& Smith, 1983; Smith \& Söderhäll, 1991). The proPO can be transformed to the active enzyme phenoloxidase (PO) by compounds such as zymosan (carbohydrates from yeast

*A uthor to whom all correspondence should be addressed at: Department of Biology, University of Southwestern Louisiana, P.O. B ox 42451, Lafayette, LA 70504, U.S.A. 
cell walls), bacterial lipopolysaccharide (LPS), urea, calcium ions, trypsin, and heat (Söderhäll et al., 1979; Söderhäll \& U nestam, 1979; Söderhäll, 1981; Söderhäll \& Häll, 1984; Leonard et al., 1985; Söderhäll et al., 1986). M ost of these compounds activate proPO through the action of a serine protease (Söderhäll, 1981; Leonard et al., 1985). Serine protease inhibitors prevent the activation for all of these compounds except for heat and urea (Leonard et al., 1985; Söderhäll et al., 1986). Proteins associated with the proPO system have been shown to present opsonic properties by provoking degranulation, encapsulation, cell adhesion of crayfish haemocytes and enhancing phagocytosis of foreign particles (Smith \& Söderhäll, 1983a; Smith \& Söderhäll, 1983b; Söderhäll et al., 1984; Söderhäll et al., 1986; Söderhäll et al., 1994).

The proPO activating system has been studied in the crayfish A stacus astacus and Pacifastacus leniusculus by Söderhäll as described above. The purpose of this work was to characterise the activation of the proPO system in the red swamp crayfish, P rocambarus clarkii, as this system has been reported to be important in the innate immunity of crustaceans. Procambarus clarkii is a commercially important species and can suffer mass mortalities due to bacterial or other pathogenic infections (Thune et al., 1991; DiéguezU ribeondo et al., 1995). Methods to determine the onset of disease are at present unknown, and it is possible that understanding the activation of the proPO system in the animals could lead to the development of diagnostic tools to assess animal health, or treatments to augment natural defence systems. The proPO system could provide an indicator system towards the development of methods to control infection. The similarity between proPO of P. clarkii and other species of freshwater crayfish has enabled us to examine some of the factors that activate this system and to test the specificity of activation by different types of molecules including trypsin, zymosan, and LPS derivatives.

\section{Materials and Methods}

CHEMICALS AND REAGENTS

Trypsin (bovine pancreas type XI), trypsin inhibitor (soybean type I-S), zymosan A from Saccharomyces cerevisiae, lipopolysaccharide (LPS) from Salmonella minnesota R5 Rc mutant, LPS detoxified (LPSdex) from S. minnesota, lipid A from S. minnesota Re 595, $\beta$-D-GICNAC-[1 $\rightarrow 6]-D-G I C N A C$ (Compound X) (Rosner et al., 1979), L-3,4-dihydroxyphenylalanine (L-DOPA), and azocasein were obtained from Sigma Chemical Co. (St. Louis, M O). Reagents for protein assays were obtained from BioRad (Richmond, CA). M orpholinopropane sulphonic acid was purchased from U nited States Biochemical Corp (Cleveland, $\mathrm{OH})$. All other chemicals and reagents were obtained from $\mathrm{F}$ isher Scientific (Houston, TX).

PREPARATION OF HAEMOLYMPH LYSATE SUPERNATANT (HLS)

Procambarus clarkii were generously provided by Dr. J. Huner from the Crayfish Research Center, U niversity of Southwestern Louisiana, Lafayette, LA, U.S.A. The animals were maintained in a water recirculating system at 
$22^{\circ} \mathrm{C}$ before they were used for experimentation. Only healthy intermolt animals were used. Haemolymph was extracted with a $2 \mathrm{ml}$ syringe and 22 gauge needle. The syringe contained $0.4 \mathrm{ml}$ of ice-cold anticoagulant buffer (AB) consisting of $0.14 \mathrm{M} \mathrm{NaCl}, 0.1 \mathrm{~m}$ glucose, $30 \mathrm{~mm}$ trisodium citrate, $26 \mathrm{~mm}$ citric acid and $10 \mathrm{~mm}$ EDTA, pH 4.6 (Smith \& Söderhäll, 1983a). For a given experiment, the extracted haemolymph from two or more animals was pooled into a sterile test tube and diluted with buffer to a final haemolymph to $A B$ volume ratio of 1:1. Diluted haemolymph was distributed into $1.5 \mathrm{ml}$ sterile E ppendorf tubes and centrifuged at $1300 \mathrm{~g}$ at $4{ }^{\circ} \mathrm{C}$ for $10 \mathrm{~min}$. The supernatant was discarded and haemocytes were resuspended in an equal volume of ice-cold rinsing buffer (RB) consisting of $10 \mathrm{~mm}$ sodium cacodylate, $0.25 \mathrm{~m}$ sucrose and $20 \mathrm{~mm} \mathrm{CaCl}, \mathrm{pH} 7.0$ (Leonard et al., 1985), and centrifuged as above for $10 \mathrm{~min}$. The supernatant was discarded and $0.2 \mathrm{ml}$ of ice-cold homogeniser buffer (HB) consisting of $10 \mathrm{~mm}$ sodium cacodylate and $20 \mathrm{~mm}$ $\mathrm{CaCl}_{2}, \mathrm{pH} 7 \cdot 0$ (Leonard et al., 1985) was added to each tube. The haemocytes were homogenised with a motor driven drill and sterile polypropylene pestle. Homogenisation was performed on ice and at full drill speed for $1 \mathrm{~min}$. HB was then added to the original haemolymph volume and centrifuged at $16000 \mathrm{~g}$ for 20 min at $4{ }^{\circ} \mathrm{C}$. The supernate was kept on ice, designated as haemocyte lysate supernate (HLS), and used as the proPO source. Additional experiments were performed using $10 \mathrm{~mm}$ M OPS (morpholinopropane sulphonic acid) in place of sodium cacodylate for the above buffers. No differences in activation or activity were noticed between the two buffers (not shown). Protein concentration of the HLS was determined using the BioRad Protein Assay System (Bio-Rad, Richmond, CA), with bovine serum albumin as the standard.

\section{PrOPO ACTIVATION AND MEASUREMENT OF PHENOLOXIDASE ACTIVITY}

Measurements of PO activity were performed in 96 well ELISA plates (Corning, NY) and colour development was measured in a spectrophotometer (Spectra Shell Plate Reader, SLT Labinstruments). Phenoloxidase (PO) activity was assayed by mixing $50 \mu \mathrm{l}$ of P. clarkii HLS with one of the following putative activators: trypsin $\left(25 \mu \mathrm{l}\right.$ of a $0.5 \mathrm{mg} \mathrm{ml}^{-1}$ solution); zymosan ( $50 \mu \mathrm{l}$ of the supernate of a $0 \cdot 2 \%$ suspension of zymosan); LPS (10 $\mu$ l of a $1 \mathrm{mg} \mathrm{ml}^{-1}$ solution); detoxified LPS (10 $\mu \mathrm{l}$ of a $1 \mathrm{mg} \mathrm{ml}^{-1}$ solution); lipid A (10 $\mu \mathrm{l}$ of a $1 \mathrm{mg} \mathrm{ml}^{-1}$ solution); and compound $X\left(10 \mu \mathrm{l}\right.$ of a $1 \mathrm{mg} \mathrm{ml}^{-1}$ solution). HB was used when necessary to bring the final volume to $100 \mu \mathrm{l}$. Samples were incubated for $45 \mathrm{~min}$ in the ELISA plates in a constant environment chamber at $22{ }^{\circ} \mathrm{C}$, followed by the addition of $50 \mu \mathrm{l}$ of L-3,4dihydroxyphenyl alanine (L-DOPA, $3 \mathrm{gl}^{-1}$ ) to each sample well. The absorbance at $492 \mathrm{~nm}$ was then measured with the reference wavelength of the spectrophotometer set at $620 \mathrm{~nm}$. Enzyme activity was expressed as change in absorbance at $492 \mathrm{~nm}$ per min per mg of protein. The effect of calcium concentration on the proPO activation by trypsin was determined by using various levels of calcium chloride $(0,5,10,20,30,50,100$, and $150 \mathrm{~mm})$ in both the RB and $H B$ buffers for the preparation of the HLS. The effect of soybean trypsin inhibitor (STI) on proPO activation was determined by the addition of trypsin inhibitor $\left(25 \mu \mathrm{l}\right.$ of a $0.5 \mathrm{mg} \mathrm{ml}^{-1}$ solution) to $50 \mu \mathrm{l}$ of $\mathrm{HLS}$ and 
incubation for $10 \mathrm{~min}$ before trypsin or zymosan was added to activate the system, followed by measuring for PO specific activity as described above. A control was run in all experiments and consisted of $50 \mu \mathrm{l} \mathrm{HLS}, 50 \mu \mathrm{l}$ of $\mathrm{HB}$, and $50 \mu$ of L-DOPA.

\section{PROTEOLYTIC ACTIVITY}

The proteolytic activity of trypsin was determined by a modification of the method of Charney \& Tomarelli (1947). This assay employs azocasein as substrate. The assay was run in plastic microcentrifuge tubes. The assay mixture consisted of $100 \mu \mathrm{l}$ of $10 \mathrm{mg} \mathrm{ml}^{-1}$ azocasein dissolved in a $5 \mathrm{mg} \mathrm{ml}^{-1}$ $\mathrm{NaHCO}_{3}$ solution ( $\mathrm{pH} 8.3$ ), trypsin $\mathrm{O}$ (blank), 5, 10, 20,30, and $50 \mu \mathrm{l}$ of a $0.5 \mathrm{mg} \mathrm{ml}^{-1}$ solution, and bicarbonate buffer $\left(5 \mathrm{mg} \mathrm{ml}^{-1}, \mathrm{pH} \mathrm{8.3)} \mathrm{necessary} \mathrm{to}\right.$ complete a total reaction mixture of $200 \mu \mathrm{l}$. The reaction mixture $(200 \mu \mathrm{l})$ was incubated at $38{ }^{\circ} \mathrm{C}$ for $5 \mathrm{~min}$. Digestion was stopped and undigested azoprotein precipitated from solution by adding $800 \mu \mathrm{l}$ of $5 \%$ trichloroacetic acid to each tube. Tubes were centrifuged at room temperature in a M icro-Centrifuge (Fisher-235B) for $5 \mathrm{~min}$. Supernatant was transferred to an ELISA plate $(100 \mu \mathrm{l})$ and mixed with $0.5 \mathrm{~N} \mathrm{NaOH}(100 \mu \mathrm{l})$. A bsorbance was measured in a spectrophotometer (Spectra Shell Plate Reader, SLT Labinstruments) at $450 \mathrm{~nm}$. The velocity constant $(K)$ of the enzymatic activity was calculated according to Charney $\&$ Tomarelli (1947). The effect of $\mathrm{Ca}^{++}$ions on this constant was checked by the addition of $\mathrm{CaCl}_{2}$ or EDTA, before the digestion step $\left(5 \mathrm{~min}\right.$ at $38{ }^{\circ} \mathrm{C}$ ), in the assay to a final concentration of $10 \mathrm{~mm}$.

\section{DATA ANALYSIS}

Phenoloxidase specific activity was obtained from the slope of regression line between the change in absorbance at $492 \mathrm{~nm}$ per $\mathrm{mg}$ protein and time in min. ANOVA analyses were applied for mean PO specific activity comparisons. Probability values $<0.05$ were considered significant. All statistical analyses were run in J M P software from SAS Institute Inc. (Cary, NC).

\section{Results}

Trypsin activation of proPO was affected by $\mathrm{Ca}^{++}$concentration in the $\mathrm{HLS}$ processing buffers (Fig. 1). M ean PO specific activity showed variability at each level of $\mathrm{Ca}^{++}$concentration, but the mean activity at 10 and $20 \mathrm{~mm} \mathrm{Ca}{ }^{++}$ was significantly higher than when 0 and $150 \mathrm{~mm} \mathrm{Ca}^{++}$was used $(P=0.006)$. The background $\mathrm{PO}$ specific activity was also affected by $\mathrm{Ca}^{++}$concentration (Fig. 1), and was found to be highest at $5 \mathrm{~mm} \mathrm{Ca}{ }^{++}(P=0.025)$. Protein concentration in the $\mathrm{HLS}$ at different $\mathrm{Ca}^{++}$concentrations varied inversely according to PO specific activity [Fig. 2(a)]. This effect is not due to the protein assay, since comparison with BSA $\left(1 \mathrm{mg} \mathrm{ml}^{-1}\right)$ detection at the same $\mathrm{Ca}^{++}$concentrations used for HLS preparation did not show a similar pattern [Fig. 2(b)]. The mean enzymatic velocity constant of trypsin caseinolytic activity was not significantly affected under each trypsin concentration $(2 \cdot 5,5$, $10,15$, and $25 \mu \mathrm{g})$ due to $\mathrm{Ca}^{++}$or EDTA $(10 \mathrm{~mm})$ addition $(P=0.2768)$. The time course of activation of proPO by trypsin could not resolve a time point that 


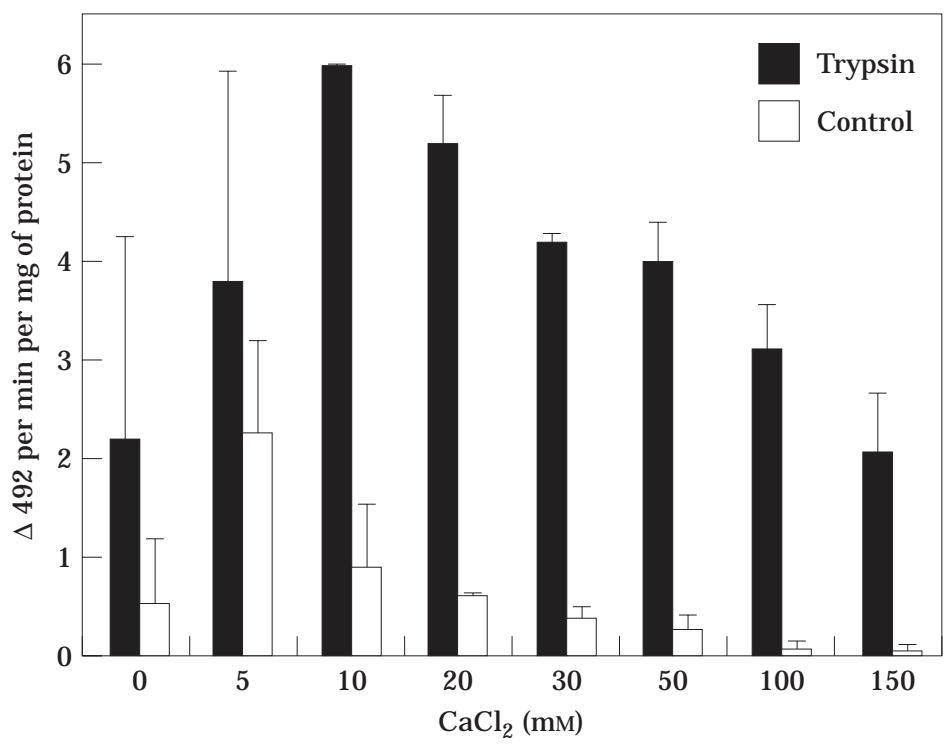

Fig. 1. Effect of $\mathrm{CaCl}_{2}$ concentration on the trypsin-dependent activation of the $P$. clarkii proPO system. Control represents background PO specific activity. PO specific activity values at each $\mathrm{CaCl}_{2}$ concentration are means of two experiments with three animals each. Error bars represent standard deviation.

showed less than full activity (Fig. 3). The mean PO specific activity was not different $(P=0.407)$ over the period of incubation.

Trypsin and zymosan $A$ were strong activators of the $P$. clarkii proPO system (Table 1). ProPO activated by trypsin and zymosan were significantly higher than the control $(P<0.001)$. The activation of proPO by trypsin and zymosan was inhibited in the presence of trypsin inhibitor $(P<0.001)$ (Table 1$)$.

The activation of proPO by LPS and LPS derivatives was investigated with 10 -fold dilutions of $1 \mathrm{mg} \mathrm{ml}^{-1}$ stock solutions. LPS was able to activate this system at concentrations of 10 and $100 \mu \mathrm{g} \mathrm{ml}^{-1}$ (P <0.001) [Fig. 4(a)]. LPSdex (deacylated LPS) was not able to activate the proPO system at all concentrations tested [Fig. 4(a)]. Lipid A, with a phosphoryl group at position 4' in the $\beta-(1 \rightarrow 6)$ glucosamine disaccharide backbone, did not show any significant $(P=0.784)$ activation of proPO at all concentrations tested [Fig. 4(b)]. Similarly, compound $\mathrm{X}$, which is a synthetic backbone of lipid $\mathrm{A}$ formed by $\beta-(1 \rightarrow 6)$ linked glucosamine disaccharide with acetyl groups linked to amino moieties at positions 2 and $2^{\prime}$ and without acyl and phosphoryl groups, did not show any significant $(P=0.817)$ activation of proPO [Fig. $4(b)$ ]. The time course of proPO activation by "complete" LPS molecules $\left(10 \mu \mathrm{g} \mathrm{ml}^{-1}\right)$ showed a delay in the activation up to $30 \mathrm{~min}$, after which PO specific activity increased compared to the control levels (Fig. 5).

\section{Discussion}

The observed effect of $\mathrm{Ca}^{++}$ions on $\mathrm{P}$. clarkii PO activity has been reported in other proPO systems (Söderhäll et al., 1979; Söderhäll, 1981; L eonard et al., 

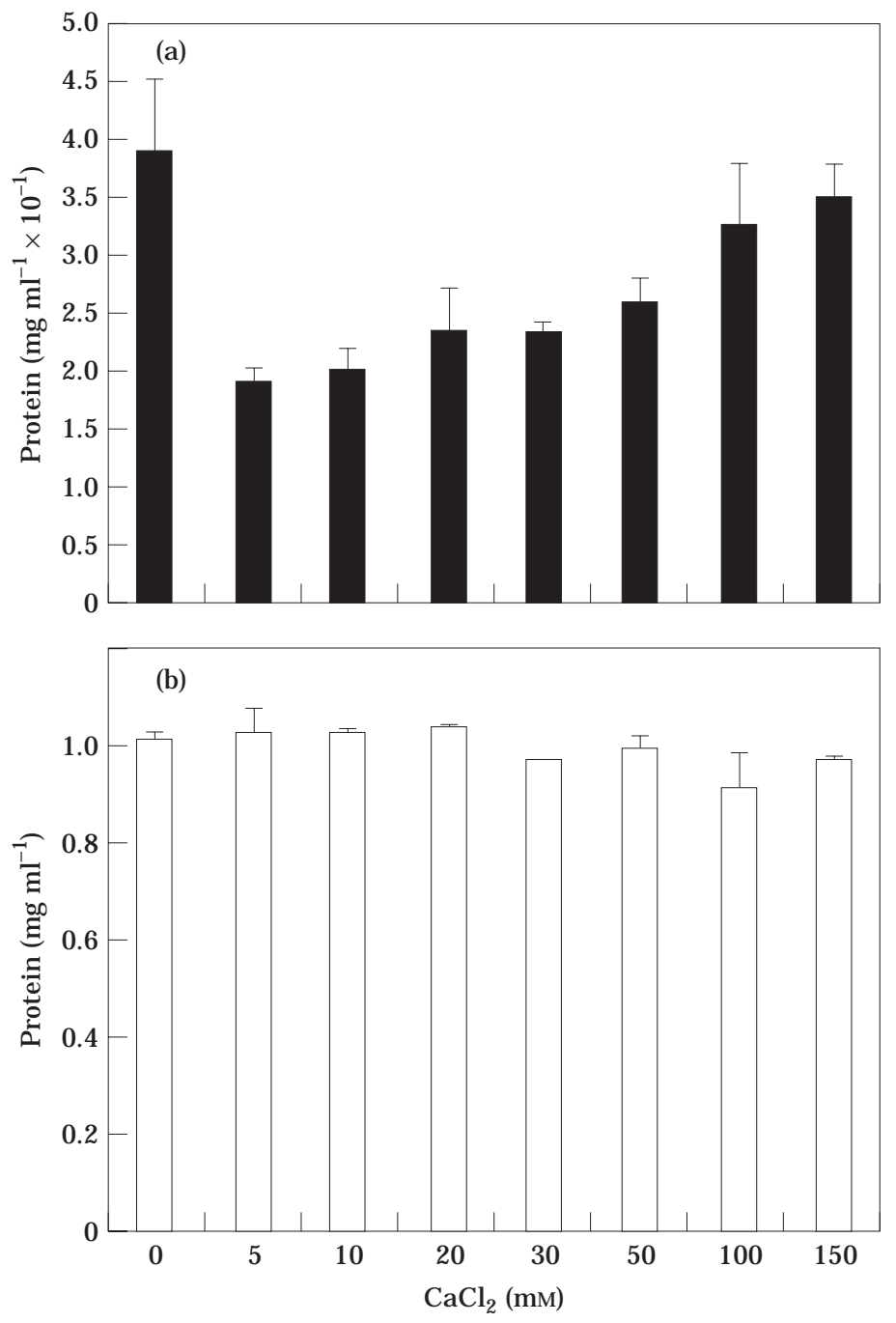

Fig. 2. E ffect of $\mathrm{CaCl}_{2}$ on (a) the yield of protein extracted in HLS preparations or (b) the colorimetric determination of the concentration of a $1 \mathrm{mg} \mathrm{ml}^{-1}$ solution of BSA. E rror bars represent standard deviation.

1985). Trypsin enzymatic activity appears to be independent of $\mathrm{Ca}^{++}$ions (Söderhäll et al., 1979). The pattern of background activity of PO clearly shows the influence of $\mathrm{Ca}^{++}$in the spontaneous activation of the proPO system ( $\mathrm{Fig}$. 1 ) that is not linked to trypsin addition. However, serine protease activity observed in crayfish HLS preparations seems to be regulated by $\mathrm{Ca}^{++}$ concentration (Söderhäll, 1981). A trypsin-like serine protease (ppA) that activates prophenoloxidase to its active form has been purified from crayfish haemocytes (Aspán et al., 1990). This proteinase is believed to be present as an inactive precursor in crayfish haemocytes (Aspán et al., 1990; Aspán \& Söderhäll, 1991). Crystalline preparations of pancreatic trypsinogen can 


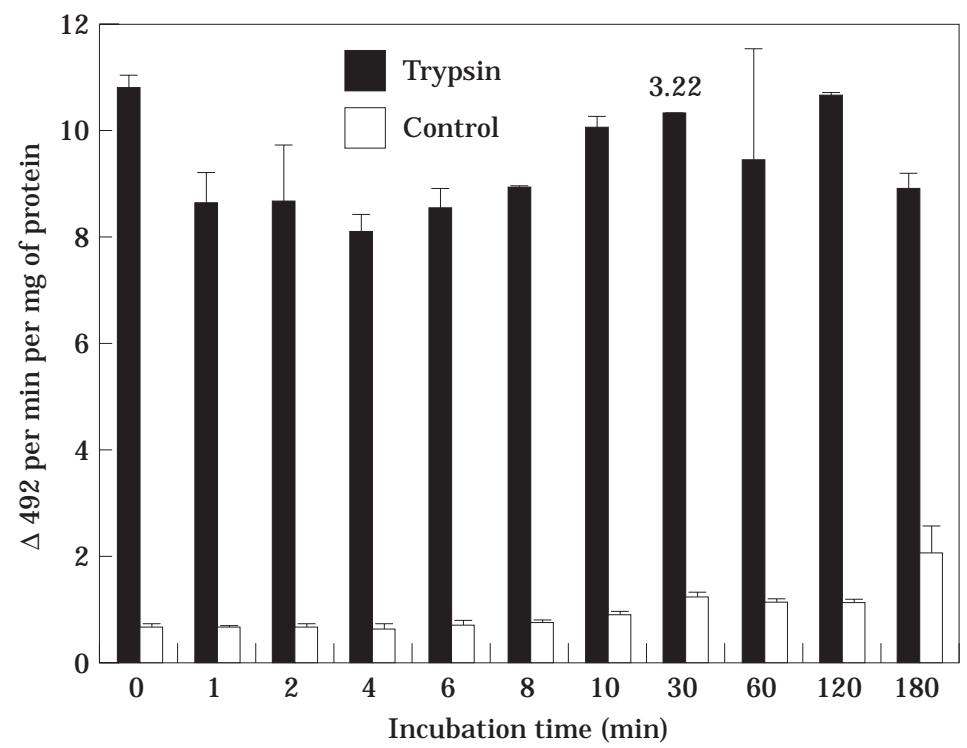

Fig. 3. Time course of proPO activation $\left(20 \mathrm{mM} \mathrm{Ca}^{++} \mathrm{HLS}\right.$ preparation) by trypsin. Control refers to background PO specific activity. Value at $30 \mathrm{~min}$ (3.22) is standard deviation. Error bars represent standard deviation.

Table 1. Activation of Procambarus clarkii proPO by trypsin and zymosan $A$, and inhibition of activation by trypsin inhibitor. Values are means ( \pm s.D.) of $n$ experiments. Each experiment was run in duplicate

HLS treatment

PO specific activity

$\Delta 492$ per min per mg protein

$\mathrm{n}$

Trypsin

Trypsin +Inhibitor

Zymosan A

Zymosan A +Inhibitor

Control

Control + Inhibitor

$\begin{array}{lr}7.75(1.82) & 8 \\ 0.37(0.18) & 2 \\ 4.88(3.07) & 6 \\ 0.94(0.55) & 2 \\ 0.49(0.16) & 11 \\ 0.32(0.09) & 2\end{array}$

autocatalytically be transformed to active trypsin without the aid of activators when at a pH of 7 to 9 (Northrop et al., 1948). This reaction can be greatly stimulated by $\mathrm{Ca}^{++}$ions (Hadorn, 1974). This stimulation seems to be related to the ability of $\mathrm{Ca}^{++}$to inhibit the formation of an inert protein product of trypsinogen in the presence of trypsin, thus enhancing the transformation of trypsinogen to trypsin (N orthrop et al., 1948). The effect of $\mathrm{Ca}^{++}$ ions observed in this and other studies on proPO activation might be related to the transformation kinetics of the putative zymogen into the active ppA. $\mathrm{H}$ owever, this argument does not explain the reduction of $\mathrm{PO}$ specific activity at higher $\mathrm{Ca}^{++}$concentrations (>20 mm) unless $\mathrm{Ca}^{++}$affects another factor (s) in the HLS preparation. $\mathrm{Ca}^{++}$is not probably required for the active enzyme, 


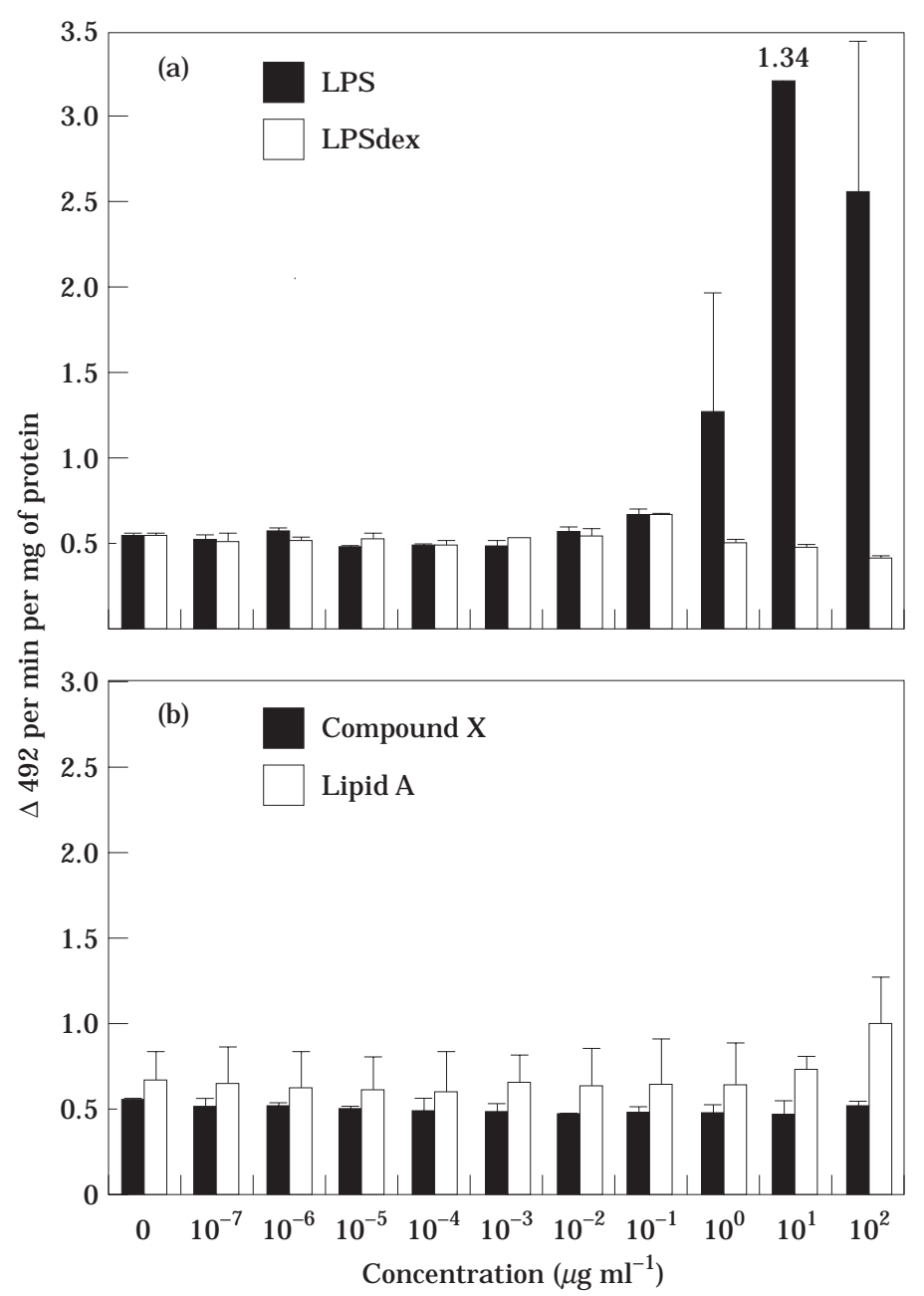

Fig. 4. E ffect of different concentrations of LPS and LPS derivatives to activate the proPO system of P. clarkii. (a) Lipopolysaccharides (LPS) from Salmonella minnesota R5 Rc mutant and lipopolysaccharides detoxified (LPSdex) from S. minnesota, value at $10^{1} \mu \mathrm{g} \mathrm{ml}^{-1}(1 \cdot 34)$ is standard deviation, (b) Compound $X$ and Lipid A from S. minnesota Re 595. PO specific activity values at each LPS and LPS derivative concentration are means of two experiments with three animals each. Error bars represent standard deviation.

since the proteolytic activity of a related serine protease (trypsin) does not require $\mathrm{Ca}^{++}$for activity, as the rate constant for enzymatic activity was not dependent upon the presence or absence of free $\mathrm{Ca}^{++}$ions. $\mathrm{A} \mathrm{CaCl}_{2}$ concentration of $5 \mathrm{~mm}$ can provoke a spontaneous coagulation process (Söderhäll, 1981). Polymerisation of proteins into high molecular weight aggregates at low $\mathrm{Ca}^{++}$concentrations $(5 \mathrm{~mm})$ can reduce the crayfish $\mathrm{HLS}$ protein content to $50 \%$ after a $10000 \mathrm{~g}$ centrifugation (Söderhäll, 1981). At higher $\mathrm{Ca}^{++}$ concentrations $(100 \mathrm{~mm})$ HLS protein concentration can be reduced to approximately $25 \%$ only after proPO and the clotting process are triggered by 


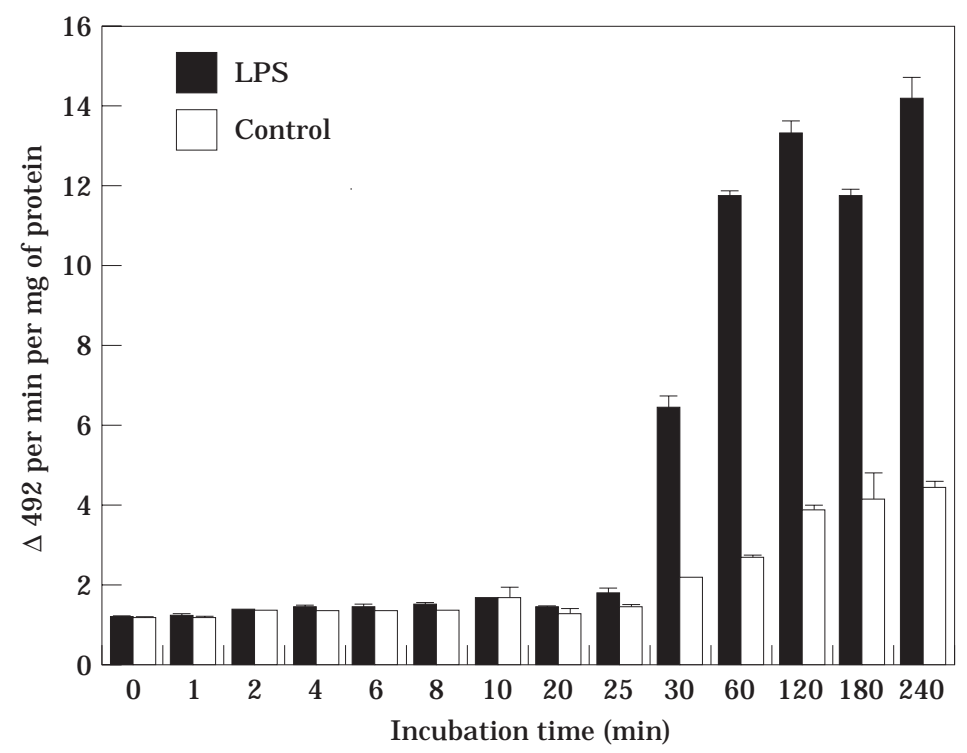

Fig. 5. Time course of proPO activation $\left(20 \mathrm{mM} \mathrm{Ca}^{++} \mathrm{HLS}\right.$ preparation) by LPS $\left(10 \mu \mathrm{g} \mathrm{ml}^{-1}\right)$. Control refers to background PO specific activity. E rror bars represent standard deviation.

$\beta$-1,3-glucan addition (Söderhäll, 1981). It has been suggested that the clotting process and PO activity are not directly linked, but are the result of endogenous serine protease activation (Söderhäll, 1981). This suggests that the concentration of $\mathrm{Ca}^{++}$during crayfish HLS preparation may have an indirect effect on its soluble protein concentration. Serine protease activation in low $\mathrm{CaCl}_{2}(5 \mathrm{~mm})$ could spontaneously trigger proPO activation and clotting processes. Polymerised HLS protein would be spun down during the $16000 \mathrm{~g}$ centrifugation step (see M ethods), resulting in the diminution of the soluble protein concentration. In the presence of increasing $\mathrm{Ca}^{++}$concentrations, serine protease activation might be reduced, thus reducing spontaneous proPO activation, but the measured soluble protein detected would increase. This might explain the inverse pattern of HLS protein concentration and proPO activation by endogenous serine protease (control) observed in this study [see Figs $1 \& 2(a)$ ]. H owever, activation of proPO by an active exogenous serine protease (trypsin) followed the same pattern as background activity. Since this protease is al ready active, $\mathrm{Ca}^{++}$ions might affect other unknown factor(s) of this enzymatic cascade that ultimately influence PO activity. Different biochemical aspects that involve $\mathrm{Ca}^{++}$ions in the activation of the proPO system are still not fully understood. The lack of detectable delay in proPO activation by trypsin (at this time resolution) suggests that a serine protease exerts its proteolytic activity directly on the pro-enzyme. This activation is stable for at least $3 \mathrm{~h}$ (see Fig. 3).

The activation of the proPO system of $\mathrm{P}$. clarkii by trypsin and zymosan, and its inhibition by a serine protease inhibitor (STI) supports the importance of a serine protease-like factor in the activation of this enzymatic cascade (see 
Table 1). Activation by zymosan shows the capability of this system to recognise non-self molecules of microbial origin. The proPO activating compound in zymosan preparations has been shown to be $\beta$-1,3-glucan (Söderhäll \& Unestam, 1979), and similar patterns of activation and inhibition of the $P$. clarkii proPO system observed in this study have been reported for other crayfish (U nestam \& Söderhäll, 1977; Söderhäll et al., 1979; Söderhäll \& U nestam, 1979; Söderhäll, 1981; Söderhäll \& Smith, 1983). The activation of proPO by zymosan and other microbial compounds can be used to test differences among species ( $P$. clarkii and $P$. zonangulus) that can be important in the commercial production of these crustaceans.

Lipopolysaccharides, molecules of the outer membrane of Gram-negative bacteria, have been shown to activate the proPO systems of crayfishes (Söderhäll \& Häll, 1984; J ohansson \& Söderhäll, 1985). This activation seems to be mediated by proteases in crayfish HLS preparations (Söderhäll \& Häll, 1984; A spán et al., 1990). In P. clarkii, the activation of the proPO system by LPS was investigated. The specificity of the activation was also tested by using different moieties of LPS. The results of these experiments showed that LPS from a rough strain of S. minnesota (R 5 Rc mutant) was able to activate P. clarkii proPO system. Rc mutant lipopolysaccharides are devoid of the 0 -somatic antigen and have an incomplete core structure formed mainly by glucose and heptose linked to lipid A via 2-keto-3-deoxy-D-manno-octonate (K DO) (Lüderitz et al., 1966; Lüderitz et al., 1982). LPSdex that bears a complete polysaccharide structure and deacylated glucosamine disaccharide backbone of lipid A was not able to activate the proPo system. Similarly, activation was not observed with lipid $A$ nor with compound $X$. These observed effects of LPS and LPS derivatives on the activation of the P. clarkii proPO system suggest that serine protease-mediated activation by these molecules could require the specific recognition or interaction with both the polysaccharide and lipid A moieties since only the "complete" LPS molecule was able to provide for the activation of this system under these conditions. Ester-linked fatty acids in lipid A may be important in this protease recognition LPS, as a derivative unable to activate the proPO system (LPSdex) has been depleted of ester-linked fatty acids (Seid \& Sadoff, 1981). Deacylated LPS has been shown to be up to 1000 -fold less active than untreated LPS in causing Limulus amoebocyte lysate to gel (Seid \& Sadoff, 1981; Ding et al., 1990). These observations with deacylated LPS are similar to the lack of activation found in the P. clarkii proPO system by LPSdex reported here. The serine protease involved in $\mathrm{P}$. clarkii proPO activation could be related to factor $\mathrm{C}$ from horseshoe crab haemocyte lysate (Nakamura et al., 1986). Factor C, a glycoprotein serine-protease zymogen, can be activated by LPS and 4'-mono- or bi-phosphorylated acylated ( $\beta 1-6)$-D-glucosamine disaccharide (synthetic Escherichia coli-type lipid A) (Nakamura et al., 1988). However, it was found that the $P$. clarkii proPO system could not be activated by the 4'-monophosphoryl lipid A. The lag time observed in proPO activation by LPS (see Fig. 5) implies the involvement of an intermediary molecule in proPO activation. A similar lag time in proPO activation by another molecule of microbial origin ( $\beta$-1,3-glucans) has been reported in the crayfish A stacus astacus (Söderhäll, 1981). Serine protease activity is involved in crayfish 
proPO activation by $\beta$-1,3-glucans and LPS (Aspán et al., 1990). Serine proteases involved in cascade reactions are composed of two distinct parts: a recognition domain and a catalytic domain. It has been proposed that recognition domains are involved in the intermolecular recognition of these proteases (Sasaki \& Ohkubo, 1994). These structures can be involved in the molecular recognition of microbial molecules which in turn activate the protease zymogen. The requirement for this recognition might explain the lag time observed in the crayfish proPO activation.

We are currently trying to isolate and identify LPS-binding proteins of $P$. clarkii through the use of LPS affinity chromatography of crayfish plasma and HLS. In this way it will be possible to determine if a serine protease of $P$. clarkii can recognise LPS itself, or if another as yet unidentified recognition factor works in conjunction with the protease to activate the proPO system. This would be required to define the sequence of events following a Gramnegative infection that triggers the activation of proPO system or other biochemical pathways involved in the innate defence of $P$. clarkii against potential bacterial pathogens.

This work was supported by funds from the Louisiana Education Quality Support Fund (LEQSF-RD-A-32) to J RD and the Department of Biology, U niversity of Southwestern Louisiana.

\section{References}

A spán, A \& Söderhäll, K. (1991). Purification of prophenoloxidase from crayfish blood cells, and its activation by an endogenous serine proteinase. Insect B iochemistry 21, 363-373.

Aspán, A., Sturtevant, J., Smith, V. J. \& Söderhäll, K. (1990). Purification and characterization of a prophenoloxidase activating enzyme from crayfish blood cells. Insect B iochemistry 20, 709-718.

Charney, J . \& Tomarelli, R. (1947). A colorimetric method for the determination of the proteolytic activity of duodenal juice. J ournal of Biological Chemistry 17, 501-505.

Diéguez-U ribeondo, J ., Huang, T., Cerenius, L. \& Söderhäll, K . (1995). Physiological adaptation of an A phanomyces astaci strain isolated from the freshwater crayfish P rocambarus clarkii. M ycological Research 99, 574-578.

Ding, H . F ., N akoneczna, I. \& H su, H . S. (1990). Protective immunity induced in mice by detoxified salmonella lipopolysaccharide. J ournal of Medical Microbiology 31, 95-102.

H adorn, B. (1974). Pancreatic proteinases. Their activation and the disturbances of this mechanism in man. M edical Clinics of $\mathrm{N}$ orth A merica 58, 1319-1331.

J ohansson, M. W. \& Söderhäll, K. (1985). Exocytosis of the prophenoloxidase activating system from crayfish haemocytes. J ournal of Comparative Physiology B 156, $175-181$.

Leonard, C., SöderhälI, K. \& Ratcliffe, N. A. (1985). Studies on prophenoloxidase and protease activity of Blaberus craniifer haemocytes. Insect Biochemistry 15, 803-810.

Lüderitz, O., Staub, A . M . \& Westphal, O. (1966). Immunochemistry of $O$ and R antigens of Salmonella and related Enterobacteriaceae. B acteriological Reviews 30, 192255.

Lüderitz, O., Freudenberg, M. A., Galanos, C., Lehmann, V., Rietschel, E. \& Shaw, D. H. (1982). Lipopolysaccharides of Gram-negative bacteria. Current Topics in Membranes and Transport 17, 79-151. 
Nakamura, T., M orita, T. \& I wanaga, S. (1986). Lipopolysaccharide-sensitive serineprotease zymogen (factor C) found in Limulus haemocytes. Isolation and characterization. European J ournal of B iochemistry 154, 511-521.

Nakamura, T., Tokunaga, F., Morita, T., Iwanaga, S., Kusumoto, S., Shiba, T., K obayashi, T. \& Inoue, K. (1988). Intracellular serine-protease zymogen, factor $C$, from hor seshoe crab haemocytes. Its activation by synthetic lipid $A$ analogues and acidic phospholipids. European J ournal of B iochemistry 176, 89-94.

N orthrop, J. H., K unitz, M \&\& Herriott, R. M . (1948). Crystalline E nzymes. p. 352. N ew Y ork: Columbia U niversity Press.

Rosner, M. R., Verret, R. C. \& K horana, H. G. (1979). The structure of lipopolysaccharide from an Escherichia coli heptoseless mutant. III. Two fatty acyl amidases from Dictyostelium discoideum and their action on lipopolysaccharide derivatives. J ournal of Biological Chemistry 254, 5926-5933.

Rowley, A. F., Ratcliffe, N. A ., L eonard, C. M ., Richards, E. H . \& Renwrantz, L. (1986). Humoral recognition factors in insects, with particular reference to agglutinins and the prophenoloxidase system. In Hemocytic and Humoral Immunity in A rthropods. (A. P. Gupta, ed.) pp. 381-406. N ew Y ork: Wiley-Interscience.

Sasaki, M.\& Ohkubo, I. (1994). M olecular recognition of proteases associated with cascade reactions. In Biological $\mathrm{Functions}$ of Proteases and Inhibitors ( $\mathrm{N}$. Katunuma, K. Suzuki, J. Travis \& H. Fritz, eds) pp.61-71. Tokyo: Japan Scientific Societies Press.

Seid, R. C., J r. \& Sadoff, J . C. (1981). Preparation and characterization of detoxified lipopolysaccharide-protein conjugates. J ournal of Biological Chemistry 256, 7305-7310.

Smith, V.J .\& Söderhäll, K . (1983a). Induction of degranulation and lysis of haemocytes in the freshwater crayfish, A stacus astacus by components of the prophenoloxidase activating system in vitro. Cell and Tissue R esearch $\mathbf{2 3 3}$, 295-303.

Smith, V. J . \& Söderhäll, K . (1983b). $\beta$-1, 3 glucan activation of crustacean hemocytes in vitro and in vivo. B iological Bulletin 164, 299-314.

Smith, V.J . \& Söderhäll, K . (1991). A comparison of phenoloxidase activity in the blood of marine invertebrates. Developmental and Comparative Immunology 15, 251261.

Söderhäll, K . (1981). Fungal cell wall $\beta$-1, 3-glucans induce clotting and phenoloxidase attachment to foreign surfaces of crayfish hemocyte lysate. D evelopmental and Comparative Immunology 5, 565-573.

Söderhäll, K . \& Häll, L. (1984). Lipopolysaccharide-induced activation of prophenoloxidase activating system in crayfish haemocyte lysate. B iochimica et B iophysica A cta 797, 99-104.

Söderhäll, K.\& Smith, V.J. (1983). Separation of the haemocyte populations of Carcinus maenas and other marine decapods, and prophenoloxidase distribution. D evelopmental and Comparative Immunology 7, 229-239.

Söderhäll, K.\& Smith, V.J . (1986). Prophenoloxidase-activating cascade as a recognition and defence system in arthropods. In H emocytic and H umoral I mmunity in A rthropods (A. P. Gupta, ed.) pp. 251-285. N ew Y ork: Wiley-Interscience.

Söderhäll, K .\& U nestam, T. (1979). A ctivation of serum prophenoloxidase in arthropod immunity. The specificity of cell wall glucan activation and activation by purified fungal glycoproteins of crayfish phenoloxidase. Canadian J ournal of M icrobiology 25, 406-414.

Söderhäll, K., Häll, L., U nestam, T. \& Nyhlén, L. (1979). A ttachment of phenoloxidase to fungal cell walls in arthropod immunity. J ournal of I nvertebrate P athology 34, 285-294.

Söderhäll, K ., V ey, A . \& R amstedt, M . (1984). Hemocyte lysate enhancement of fungal spore encapsulation by crayfish hemocytes. Developmental and Comparative I mmunology 8, 23-29.

Söderhäll, K., Smith, V.J.\& J ohansson, M. W. (1986). Exocytosis and uptake of bacteria by isolated haemocyte populations of two crustaceans: evidence for 
cellular co-operation in the defence reactions of arthropods. Cell and Tissue R esearch 245, 43-49.

Söderhäll, K ., Cerenius, L. \& J ohansson, M. W. (1994). The prophenoloxidase activating system and its role in invertebrate defence. A nnals of the $\mathrm{N}$ ew $\mathrm{Y}$ ork A cademy of Sciences 712, 155-161.

Thune, R. L., Hawke, J . P.\& Siebeling, R. J . (1991). Vibriosis in the red swamp crawfish. J ournal of A quatic A nimal Health 3, 188-191.

Unestam, T.\& Söderhäll, K. (1977). Soluble fragments from fungal cell walls elicit defence reactions in crayfish. $\mathrm{N}$ ature $\mathbf{2 6 7}, \mathbf{4 5 - 4 6 .}$ 